Open Pharmaceutical Sciences Journal
Bentham OPen
CrossMark
Content list available at: www.benthamopen.com/PHARMSCI/
DOI: $10.2174 / 1874844901603010025$

\title{
Antioxidant Capacity and Free Radical Scavenging Effects on Nigerian Pineapple (Ananas cormosus) and Orange (Citrus sinensis) Pulp Extracts at Different Levels of Ripeness
}

\author{
Stella Chintua Ortutu ${ }^{1}$ and Matthew Olaleke Aremu, ${ }^{2, *}$

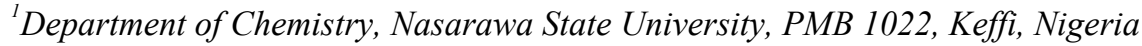 \\ ${ }^{2}$ Department of Chemical Sciences, Federal University Wukari, PMB 1020, Taraba State, Nigeria
}

Received: September 05, 2015

Revised: January 01, 2016

Accepted: April 06, 2016

\section{Abstract:}

Background:

There is a need to shift interest from the use of synthetic antioxidants which are harmful to the use of natural antioxidants from fruits and vegetables for the prevention of lipid oxidation.

\section{Objective:}

The total polyphenols, flavonoids, lipid-soluble antioxidants (CALT) and radical scavenging ability of the pulp extracts of pineapple (Ananas cormosus) and orange (Citrus sinensis) were investigated at different maturation stages for the purpose of determining their antioxidant capacity and the possibility of using these fruits at every maturation stage for the prevention of lipid oxidation.

\section{Methods:}

The pulps of these fruits were extracted at different levels of ripeness; unripe (UR), about to ripe (AR) and ripe (RP). The extracted pulps were freeze-dried and used for the analysis. The total phenol content was determined by spectrophotometry (Folic Ciocalteu's method) while 1, 1-diphenyl-2-picrylhydrazyl (DPPH) was used for the radical scavenging ability. The various antioxidant capacities were compared with standard antioxidants such as gallic acid, rutin, $\alpha$-tocophenol and ascorbic acid.

\section{Results:}

The results showed that the two edible fruits investigated at different levels of ripeness possess high quality antioxidants (those that can scavenge free radicals, function as metal chelators or donate hydrogen atoms). Radical scavenging ability of the fruit pulps was significantly affected $(\mathrm{P}<0.05)$ by the different level of ripeness.

\section{Conclusion:}

The unripe fruits had the highest antioxidant properties suggesting that the antioxidant capacity of the fruits decreased as the fruits ripened.

Keywords: Antioxidant capacity, levels of ripeness, orange, pineapple.

\section{Graphical Abstract}

DPPH is common abbreviation for an organic chemical compound 2,2-diphenyl-1-picrylhydrazyl. It is composed of stable free radical molecules.

\footnotetext{
* Address correspondence to this author at Department of Chemical Sciences, Federal University Wukari, PMB 1020, Taraba State, Nigeria; Tel: +2348065611658; E-mail: lekearemu@gmail.com
} 


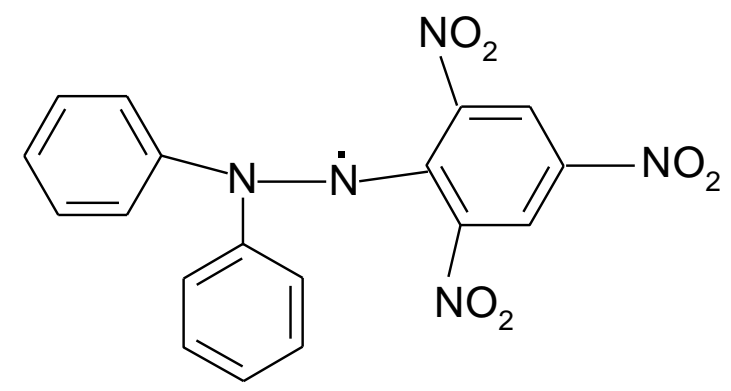

\section{INTRODUCTION}

Lipid oxidation affects several biological systems and it is associated with cardiovascular disease and cancers [1]. It is also the cause of rancidity in foods which affects the color, flavor, texture and the nutritional value of foods $[2,3]$. Free radicals chain reaction is the major cause of lipid oxidation and occurs when free radicals form chain reaction with unsaturated triacylglycerols/phospholipases and monoatomic/triatomic oxygen.

Antioxidants are substances that significantly reduce or prevent the oxidation of other molecules when in small amounts. They can come from natural products or be made commercially. In the past, lipid oxidation has been controlled with the use of synthetic antioxidants such as butylated hydroxy touluene, propylgallate and tert-butylhydroquinone [4 - 6]. These synthetic antioxidants are suspected to be responsible for liver damage and carcinogenesis in laboratory animals $[7,8]$. It is therefore necessary to shift interest from the use of synthetic antioxidants which are harmful to the use of natural antioxidants from fruits and vegetables for the prevention of lipid oxidation. Nigeria is blessed with fruits which are grown all over the 36 states of the country including the Federal Capital Territory (FCT). These fruits are under-utilized for antioxidant properties and should therefore be studied thoroughly to determine their antioxidant capacity.

Pineapple (Ananas cormosus) makes up the family Bromelica. It was first domesticated in the high plateaus of central South Africa for its fiber content before the Europeans first saw it in the Caribbean. Thereafter, cultivation spread to warm regions around the globe [9]. When the fruit is mature, the skin is greenish; when it is ripe, the skin is yellowish, greenish or greenish yellow depending on the variety $[10,11]$. Pineapple fruit is considered a highly nutritious fruit because it contains a high level of vitamin $C$ and $\beta$-carotene [12].

Orange (Citrus sinensis) belongs to the family Rutarea, the most widely grown citrus specie. It is composed of an external layer (peel) formed by flavedo (epicarp or exocarp), albedo (mesocarp) and an inner material called endocarp that contains the juice. There are different varieties of orange fruit, which include the sweet orange (Citrus sinensis), the

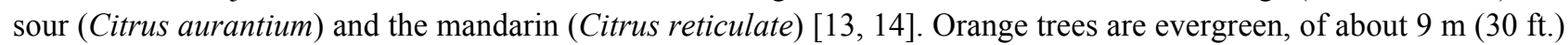
in height. The unripe fruit is greenish while the ripe fruit could be greenish or yellowish.

Considering the adverse effect of lipid oxidation in medicine and food, moreso no information is available on the antioxidant capacity and free radical scavenging ability of pulp extracts of pineapple and orange at different levels of ripeness (unripe, about to ripe and ripe) grown in the south- south and Federal Capital Territory (FCT). The present study was to determine total phenol content, flavonoids, lipid-soluble antioxidants (CALT) and radical scavenging ability of the pulp extracts of pineapple (Ananas cosmosus) and orange (Citrus sinensis) grown in Nigeria at different levels of ripeness.

\section{MATERIALS AND METHODS}

\subsection{Collection of Samples}

Pineapple (Ananas cormosus) and orange (Citrus sinensis) fruits were harvested from their trees in August, 2014 from Ugheli in Edo state of Nigeria and Kubwa town in the FCT, Abuja, Nigeria, respectively. Based on visual observations of color, texture and flavor, the fruits were categorized into unripe (UR), about to ripe (AR) and ripe (RP). The peel of the fruits was removed and the fruits were sliced horizontally into halves with a sharp knife and cut into small sizes. The categorized and sliced fruit pulps were taken to the medicinal Department of National Institute of Pharmaceutical Research and Development (NIPRD) Idu, FCT- Abuja for further treatments and analyses. 


\subsection{Preparation of Samples}

The categorized and sliced fruits were weighed, homogenized using a domestic blender, filtered using a cheese cloth and freeze-dried. The freeze-dried samples were stored in a sample bottle and used for analysis.

\subsection{Chemicals and Reagents}

Chemicals of analytical grade (British Drug House) were used for the analysis. These include: Folin-Ciocalteu's phenol reagent, gallic acid, aluminium chloride, potassium acetate, $70 \%$ aqueous methanol, 1, 1-diphenyl-2picryhydrazyl (DPPH), ascorbic acid, rutin, absolute ethanol, sulphuric acid, sodium phosphate and ammonium molybdate.

\subsection{Total Phenolic Content Determination}

The total phenolic content was measured using Folin-Ciocalteu reagent as described by Jagadish et al. [15]. $4.0 \mathrm{mg}$ of each freeze-dried categorized sample was dissolved in $4.0 \mathrm{ml}$ of $70 \%$ aqueous methanol. $0.6 \mathrm{ml}$ of the methanoic extracts was mixed with $0.5 \mathrm{ml}$ of 1:10 dilution of Folin-Ciocalteu phenol reagents and $0.4 \mathrm{ml}$ of $0.7 \mathrm{M} \mathrm{Na}_{2} \mathrm{CO}_{3}$ solution. The solution was incubated for $10 \mathrm{~min}$ at a constant temperature of $100{ }^{\circ} \mathrm{C}$ in a water bath. After incubation, the solution was ice cooled and diluted with $1.5 \mathrm{ml}$ distilled water and measured at an absorbance of $760 \mathrm{~nm}$. The total polyphenol in the fruits was obtained from a standard curve of gallic acid ranging from 0.001 to $0.5 \mathrm{mg} / \mathrm{ml}$ (Pearson's correlation coefficient: $\left.\mathrm{r}^{2}=0.9250\right)$. Total phenol content was expressed as milligram of gallic acid equivalent (GAE) / g weight of each categorized fruit pulp tissue.

\subsection{Measurement of Total Flavonoids}

The total flavonoid was spectro-photometically determined as described by Grant [2]. $1.0 \mathrm{mg} / \mathrm{ml} \mathrm{methanoic} \mathrm{extract}$ of each categorized sample was mixed with $10 \% 0.1 \mathrm{ml}$ aluminium chloride; $0.1 \mathrm{ml}$ of $1.0 \mathrm{M}$ potassium acetate and 2.8 $\mathrm{ml}$ distilled water was added. The solution was vortexed and allowed to sit for $40 \mathrm{~min}$ at $25^{\circ} \mathrm{C}$ and the absorbance measured at $415 \mathrm{~nm}$. The total flavonoid content of the fruits was quantified based on the standard curve prepared for rutin at concentrations of 0.004 to $1.0 \mathrm{mg} / \mathrm{ml}$ (Pearson's correlation coefficient: $\mathrm{r}^{2}=0.982$ ). The total flavonoid was expressed as milligram of rutin equivalent/g weight of each categorized fruit pulp tissue.

\subsection{Determination of Total Lipid-Soluble Antioxidant Capacity (CALT)}

A spectro-photometric method developed by Prior et al. [16] was used to determine the total lipid antioxidant capacity of the fruits. $0.2 \mathrm{ml}$ of $1.0 \mathrm{mg} / \mathrm{ml}$ of each freeze-dried categorized sample was dissolved in $0.2 \mathrm{ml}$ absolute ethanol. The ethanoic extract was mixed with $1.0 \mathrm{ml}$ of phosphomolybdenium reagent $(32 \mathrm{mM}$ sodium phosphate +4 $\mathrm{mM}$ ammonium molybdate and $0.6 \mathrm{M} \mathrm{H}_{2} \mathrm{SO}_{4}$ ). The mixture was homogenized and incubated at $95^{\circ} \mathrm{C}$ for 90 min and the absorbance measured at $695 \mathrm{~nm}$. CALT is expressed as equivalents of $\alpha$-tocophenol. A standard curve was constructed with different amounts of $\alpha$-tocophenol dissolved in ethanol. An extinction coefficient (E) of $137 \mathrm{Nm}^{-1}\left(\mathrm{r}^{2}=0.9998\right)$ was used for quantification.

CALT (mmol $\alpha$-tocophenol/g fruit pulp tissue) $=\mathrm{A}_{695} \mathrm{E}^{-1} \mathrm{ERV} \times \mathrm{SV}^{-1} \times \mathrm{EV} \times \mathrm{M}^{-1}$

Where: $\mathrm{A}_{695}$ is the absorbance at $695 \mathrm{~nm}$.

$\mathrm{E}^{-1}$ is the inverse of the extinction coefficient.

$\mathrm{RV}$ is the overall reaction volume.

$\mathrm{SV}$ is the sample volume used in the reaction.

$\mathrm{EV}$ is the volume of solvent used in the extraction of the plant material analyzed.

$\mathrm{M}$ is the amount (grams) of fresh plant material.

\subsection{Determination of Radical Scavenging Ability}

The scavenging ability of the samples on the stable free radical DPPH was evaluated using the method described by Grant [2]. $20.0 \mathrm{mg}$ of each freeze-dried categorized samples was added to $0.078 \mathrm{mg} / \mathrm{ml}$ methanol solution of DPPH. The mixture was allowed to stand without light for $30 \mathrm{~min}$ and the absorbance was measured at $517 \mathrm{~nm}$. The DPPH radical scavenging effect was expressed as a percent inhibition of the DPPH radical and determined according to the equation bellow: 


$$
\text { Radical scavenging }=\frac{A B S \text { control }- \text { ABS sample }}{A B S \text { control }} \times 100
$$

Ascorbic acid solution was used as a positive control for antioxidant activity.

\subsection{Statistical Analysis}

Data were expressed as means $\pm \mathrm{SD}$ of three independent experiments. A probability $\mathrm{P}<0.05$ was considered significant. Coefficient of variation in $\%$ was also used.

\section{RESULTS AND DISCUSSION}

\subsection{Effects of Total Phenolic Content}

The total phenolic contents are essential in the assay of antioxidant capacity of fruits and vegetables [7, 17]. Recent findings also suggest the role of polyphenolic compounds as protective agents against cardiovascular disease and breast, gastrointestinal and skin cancers due to their oxidative/antioxidative potential or their ability to act as free radical scavengers [18]. Table 1 shows the mean total phenolic concentrations of unripe (UR), about to ripe (AR) and ripe (RP) pineapple and orange fruit pulps. One milligram of the unripe (UR) fruit pulps contain concentrations ranging from 0.49 to $0.66 \mathrm{mg}$ of gallic acid equivalents of phenolic compounds, about to ripe (AR) ranged from 0.36 to $0.63 \mathrm{mg}$ of gallic acid equivalents of phenolic compounds and ripe (RP) ranged from 0.45 to $0.64 \mathrm{mg}$ of gallic acid equivalents of phenolic compounds. These concentrations of polyphenols can play an important role in antioxidant ability of these fruits. This is because it has been suggested that up to $1 \mathrm{~g}$ of polyphenolic compounds (from a diet rich in fruits and vegetables ingested daily has inhibitory effects on mutagenesis and carcinogenesis in humans [7, 19]. There is no significant difference at $\mathrm{P}<0.05$ in the total phenolic content of the fruits though the polyphenols in orange pulp is greater than that in pineapple at all the levels of ripeness examined. The result showed that the total phenolic content of $\mathrm{UR} \geq \mathrm{RP}>\mathrm{AR}$ for both pineapple and orange pulp extracts suggesting that as the fruit pulps ripens, the total polyphenols decreased. The coefficient of variation ranged from $3.13 \%$ in orange to $16.28 \%$ in pineapple.

Table 1. Total phenols, flavonoids and lipid soluble antioxidant capacity (CALT) for unripe (UR), about to ripe (AR) and ripe (RP) pineapple and orange fruitpulps. Mean values $(n=3)$.

\begin{tabular}{|c|c|c|c|}
\hline Sample & Total Phenols (mg/g) & Flavonoids (mg/g) & CALT (mmol/g) \\
\hline \multicolumn{4}{|c|}{ Pineapple } \\
\hline $\mathbf{U R}$ & $0.49 \pm 0.01$ & $0.03 \pm 0.02$ & $0.014 \pm 0.01$ \\
\hline $\mathbf{A R}$ & $0.36 \pm 0.03$ & $0.01 \pm 0.03$ & $0.009 \pm 0.02$ \\
\hline $\mathbf{R P}$ & $0.45 \pm 0.02$ & $0.03 \pm 0.01$ & $0.006 \pm 0.02$ \\
\hline Mean & 0.43 & 0.02 & 0.010 \\
\hline SD & 0.07 & 0.01 & 0.004 \\
\hline CV $(\%)$ & 16.28 & 50.00 & 40.00 \\
\hline \multicolumn{4}{|c|}{ Orange } \\
\hline $\mathbf{U R}$ & $0.66 \pm 0.02$ & $0.06 \pm 0.01$ & $0.022 \pm 0.03$ \\
\hline $\mathbf{A R}$ & $0.63 \pm 0.02$ & $0.04 \pm 0.01$ & $0.016 \pm 0.02$ \\
\hline RP & $0.64 \pm 0.03$ & $0.06 \pm 0.02$ & $0.015 \pm 0.02$ \\
\hline Mean & 0.64 & 0.06 & 0.018 \\
\hline SD & 0.02 & 0.01 & 0.004 \\
\hline CV $(\%)$ & 3.13 & 16.60 & 22.22 \\
\hline
\end{tabular}

$\mathrm{UR}=$ Unripe $; \mathrm{AR}=$ About to ripe $\mathrm{RP}=\mathrm{Ripe} ; \mathrm{SD}=$ Standard deviation $; \mathrm{CV}=$ Coefficient of variation in percentage.

\subsection{Effect of Total Flavonoids}

Flavonoids are secondary metabolites which have been found to have antioxidant, antibacterial and antimicrobial properties [20 - 22]. Table shows the mean total flavonoid concentration values for unripe (UR), about to ripe (AR) and ripe (RP) pineapple and orange fruit pulps. The amount of total flavonoids (mg rutin/g tissue) for UR pineapple and orange was 0.03 and 0.06 respectively. AR $(0.01 \& 0.04)$ and $R P(0.03 \& 0.06)$ for pineapple and orange fruit pulps respectively. At $\mathrm{P}<0.05$, the total flavonoids content of the fruit pulps were significantly affected by their level of ripeness. The result showed that the fruits at different maturation stages are good sources of flavonoids and that the flavonoid content of the unripe fruit was highest, decreased when the fruit was about to ripe and increased again when the fruit was ripe. The coefficient of variation ranged from $16.60 \%$ in orange to $50 \%$ in pineapple. 


\subsection{Effect of Lipid Soluble Antioxidant Capacity (CALT)}

The lipid-soluble antioxidant capacities of the fruits were studied using $\alpha$-tocophenol as a standard. Table 1 shows the mean lipid-soluble antioxidant capacity of UR, AR and UR fruit pulps. There is no significant difference at $\mathrm{P}<0.05$ in the lipid soluble antioxidant capacity of the fruits at different levels of ripeness. The lipid soluble antioxidant capacity of the fruits decreased as the fruit ripened. This suggests that the fruits are likely to contain more water-soluble antioxidants as they ripen.

\subsection{Radical Scavenging Effect}

The scavenging ability of an antioxidant is measured by its ability to quench the stable DPPH radical with maximum absorption at $517 \mathrm{~nm}[2,23]$. Table 2 shows the DPPH free radical scavenging ability of pineapple and orange fruit pulps at different levels of ripeness. The results showed that pineapple and orange fruit pulps are good radical scavengers at different levels of ripeness. The unripe (UR) fruit pulp has the highest scavenging activities (65.80 $\%$ and $86.33 \%$ ) respectively for pineapple and orange fruit pulps. This was followed by RP with \% reduction of 63.93 for pineapple and 77.77 for orange. AR had the least \% reduction of 61.17 for pineapple and 76.33 for orange. The radical scavenging ability of the fruit pulps was significantly affected $(\mathrm{P}<0.05)$ by their level of ripeness. The radical scavenging capacity of the fruit pulps examined decreased with ripening.

Table 2. Radical scavenging activity of pineapple and orange at different maturation stages. Mean values $(n=3)$.

\begin{tabular}{|c|c|c|c|c|c|c|}
\hline \multirow{2}{*}{ Sample } & \multicolumn{3}{|c|}{ Radical scavenging (\% reduction) } & \multirow{2}{*}{ Mean } & \multirow{2}{*}{ SD } & \multirow{2}{*}{ CV $(\%)$} \\
\hline & $\mathbf{U R}$ & $\mathbf{A R}$ & $\mathbf{R P}$ & & & \\
\hline Pineapple & $65.80 \pm 2.34$ & $61.17 \pm 0.12$ & $63.93 \pm 3.33$ & 63.63 & 2.33 & 3.66 \\
\hline Orange & $86.33 \pm 2.49$ & $76.33 \pm 10.02$ & $77.77 \pm 9.47$ & 80.14 & 5.41 & 6.75 \\
\hline
\end{tabular}

$\mathrm{UR}=$ Unripe; $\mathrm{AR}=$ About to ripe; $\mathrm{RP}=\mathrm{Ripe} ; \mathrm{SD}=$ Standard deviation; $\mathrm{CV}=$ Coefficient of variation in percentage.

\section{CONCLUSION}

The results showed that pineapple and orange fruit pulps possessed high quality antioxidants (those antioxidants that can scavenge free radicals, function as metal chelators or donate hydrogen atoms) at different levels of ripeness. This observation may be as a result of phytochemicals such as flavonoids and polyphenols present in the fruits. The extracts of these fruits at different levels of ripeness could be used to prevent lipid oxidation.

\section{CONFLICT OF INTEREST}

The authors confirm that this article content has no conflict of interest.

\section{ACKNOWLEDGEMENTS}

The authors are grateful to the management of the National Institute of Pharmaceutical Research and Development (NIPRD), Idu- Abuja for the use of their laboratories and equipment; Dr. F. Tarfa, the Research Fellow, Mr. Ache, the Technologist and all the staff of the Department of Medicinal Chemistry for their support.

\section{REFERENCES}

[1] Fortunato G, Di Taranto MD. Polymorphisms and the expression of genes encoding enzymes involved in cardiovascular diseases. Clin Chim Acta 2007; 381(1): 21-5. [http://dx.doi.org/10.1016/j.cca.2007.02.018] [PMID: 17368599]

[2] Grant GH. Antioxidant capacity of pawpaw pulp extraction from different levels of ripeness. Col of Health and Human Services Ohio 2008; 32: 48-50.

[3] Aremu MO, Olaofe O, Audu SS, Ijalana DM. Biochemical evaluation of fermented white maize (Zea mays L.) blended with scarlet runner bean (Phaseolus coccineous L.). TONUTRAJ 2011; 4: 163-71.

[4] Kim DO, Jeong SW, Lee CY. Antioxidant capacity of phenolic phytochemicals from various cultivars of plums. Food Chem 2003; 81(4): 321-6.

[http://dx.doi.org/10.1016/S0308-8146(02)00423-5]

[5] St Angelo AJ. Lipid oxidation on foods. Crit Rev Food Sci Nutr 1996; 36(3): 175-224. [http://dx.doi.org/10.1080/10408399609527723] [PMID: 8744604]

[6] Quadri MF, Malviya R, Sharma PK. Biomedical applications of interpenetrating polymer network system. Open Pharm Sci J 2015; 2: 21-30. [http://dx.doi.org/10.2174/1874844901502010021] 
[7] Biswas M, Haldar PK, Ghosh AK. Antioxidant and free-radical-scavenging effects of fruits of Dregea volubilis. J Nat Sci Biol Med 2010; 1(1): 29-34.

[http://dx.doi.org/10.4103/0976-9668.71670] [PMID: 22096333]

[8] Bartosz G. Oxidative stress in plants. Acta Physiol (Oxf) 1997; 19: 47-64.

[9] Kongsuwani P, Suthiluki T, Theppakorni V. Srilaong, Setha S. Bioactive compounds and antioxidant capacities of phulae and nariglae pineapple. Afr J of Food \& Agro-industry 2009; 6: 44-50.

[10] Hart DJ, Scoth KJ. Development and evaluation of an HPLC method for the analysis of carotenoids in foods, and the measurement of the carotenoid content of vegetables and fruits commonly consumed in the UK. Food Chem 1995; 54: 101-11. [http://dx.doi.org/10.1016/0308-8146(95)92669-B]

[11] Aremu MO, Olaofe O. Fat and fatty acid composition of some plant foods found in Nigeria. A review. Ind J Botanical Res 2007; 3: 328-48.

[12] Gardener PT, White TA, McPhail DB, Duthie GG. The relative contributions of vitamin C carotenoids and phenolics to the antioxidant potential of fruit juice. Food Chem 2000; 6: 471-4. [http://dx.doi.org/10.1016/S0308-8146(99)00225-3]

[13] Morton JF. Fruits of Warm Climates. Miami, FL 1987; pp. 134-42.

[14] Nicolosi E, Deng ZN, Gentile A, La Malfa S, Continella G, Tribulato E. Citrus phylogeny and genetic origin of important species as investigated by molecular markers. Theor Appl Genet 2000; 100(8): 1155-66. [http://dx.doi.org/10.1007/s001220051419]

[15] Jagadish LK, Krishnan VV, Shenbnagraman R, Kaviyarasan V. Comparative study on the antioxidant, anticancer and antimicrobial property of Agaricus bisporus imbach before and after boiling. Afr J Biotechnol 2009; 12: 654-61.

[16] Prior RL, Wu X, Schaich K. Standardized methods for the determination of antioxidant capacity and phenolics in foods and dietary supplements. J Agric Food Chem 2005; 53(10): 4290-302. [http://dx.doi.org/10.1021/jf0502698] [PMID: 15884874]

[17] Guangzhon R. Antioxidant capacities and total phenolic contents of 56 wild fruits from South China. J Food Nutr Health 2010 ; 15 : $602-17$.

[18] Turner S, Cogoi L, Isolabella S, Filip R, Anesini C. Evaluation of the antioxiodant activity and polyphenols content of Ilex paraguariensis (Mate) during industrialization. J Food Sci Techn 2011; 3: 23-30.

[19] Olajire AA, Azeez I. Total antioxidant, phenolics, flavonoids and ascorbic acid contents of Nigerian vegetables. Afr J Food Sci Techn 2011; 2: $22-9$.

[20] Osarumwense PO, Okunrobo L. Phytochemical composition of Acalypha lispida (Euphorbiaceae). Inter J Chemical Sci 2011; 4: 172-5.

[21] Leja M, Mareezek A, Ben J. Antioxidant properties of two apple cultivars during long term storage. Food Chem 2003; 80: $303-7$. [http://dx.doi.org/10.1016/S0308-8146(02)00263-7]

[22] Joshi D, Patel R, Patel N, Patel D, Pandya C. Antimicrobial evaluation of leaf and stem extract of Cordial macleodii. Open Pharm Sci J 2014; 1: $1-3$. [http://dx.doi.org/10.2174/1874844901401010001]

[23] Lopes M, Miranda M, Moura C, Filho J. Bioactive compound and total antioxidant capacity of cashew apples during ripening of early dwarf clones. J Food Sci Techn 2012; 36: 430-500.

(C) Ortutu and Aremu ; Licensee Bentham Open.

This is an open access article licensed under the terms of the Creative Commons Attribution-Non-Commercial 4.0 International Public License (CC BY-NC 4.0) (https://creativecommons.org/licenses/by-nc/4.0/legalcode), which permits unrestricted, non-commercial use, distribution and reproduction in any medium, provided the work is properly cited. 